\title{
The Nature, Sources, Detections and Regulations of Mycotoxins That Contaminate Foods and Feeds Causing Health Hazards for Both Human and Animals
}

\author{
Osama O. Ibrahim¹, Mirjana Menkovska² \\ ${ }^{1}$ Biotechnology and Food Safety USA, Gurnee, IL, USA \\ ${ }^{2}$ Food Science S.S. Cyril and Methodius University, Skopje, Macedonia \\ Email: bioinnovation04@yahoo.com
}

How to cite this paper: Ibrahim, O.O. and Menkovska, M. (2019) The Nature, Sources, Detections and Regulations of Mycotoxins That Contaminate Foods and Feeds Causing Health Hazards for Both Human and Animals. Journal of Agricultural Chemistry and Environment, 8, 33-57.

https://doi.org/10.4236/jacen.2019.81004

Received: January 12, 2019

Accepted: February 16, 2019

Published: February 19, 2019

Copyright $\odot 2019$ by author(s) and Scientific Research Publishing Inc. This work is licensed under the Creative Commons Attribution International License (CC BY 4.0).

http://creativecommons.org/licenses/by/4.0/

cC) (7) Open Access

\begin{abstract}
Mycotoxins are toxic secondary metabolites produced by fungus kingdom. Fungi (molds) under aerobic and optimum conditions of humidity and temperature consume nutrients for proliferation and mycotoxin production (secretion). There are seven major groups of mycotoxins produced by different species of toxigenic fungal genus. Mycotoxins production from these toxigenic fungi depends on the surrounding intrinsic and extrinsic environments. These seven mycotoxins groups that contaminate grains, foods and animal feeds are: Aflatoxins, Trichothecene, Ochratoxins, Ergot alkaloid (Ergolin), Fumonisins, Patulin, and Zearalenone. These mycotoxins are capable of causing health hazards and death for both human and animals by effecting mammalian cells, causing a number of problems in normal cell function and a wide variety of clinical symptoms of diseases. These mycotoxins are varied in their toxicity depending on the infected host (human or animal) and the host susceptibility (immunity). The major concern of food and feed industries is the contamination of food products and animal feed supplies by these mycotoxins. Worldwide Health Organization (WHO), and Food and Agriculture Organization (FAO) are responsible to regulate the acceptable (tolerable) levels of these mycotoxins in grains, food and feed supplies to ensure the safety and health for both human and animals. Understanding fungal ecology and factors that affect fungal proliferation and mycotoxins production by these toxigenic fungi in agriculture crops as raw materials for both human food and animal feed products, plus understanding the chemistry and property of these mycotoxins, methods of detection, illness symptoms, and comply with regulatory guidance established by
\end{abstract}


World Health Organization (WHO)/Food and Agriculture Organization (FAO) are key factors to prevent or minimize foods/feeds contamination and the toxicity of these mycotoxins for both human and animals health, plus reducing economical loss.

\section{Keywords}

Mycotoxins, Toxigenic Fungi, Aspergillus, Fusarium, Penicillium, Claviceps, Aflatoxins, Trichothecene, Ochratoxins, Ergot Alkaloid (Ergolin), Fumonisins, Patulin, Zearalenone

\section{Introduction}

Mycotoxins are natural toxic chemical compounds produced as secondary metabolites by certain types of toxigenic fungi (molds) that proliferate (grow) on agriculture crops such as, grains, cereals, dried fruits, nuts, and spices. Foods and animal feeds produced from these mycotoxins contaminated agriculture crops are health hazard for both human and animals. These types of toxigenic fungi [1] can proliferate under optimum conditions of temperature and humidity either before or after crops harvesting, during crops storage, and in processed food/feed products. Mycotoxins produced by these toxigenic fungi are mostly chemically stable compounds and toxic at very low concentration in grains, foods, and animal feeds.

These types of fungi producing mycotoxins have been identified, and ecology factors that enhance proliferation and production (secretion) of mycotoxins have been studies [2]. These studies assist in protecting human and animals from the toxicity of contaminated foods or feeds by these mycotoxins. There are hundreds of mycotoxins produced by fungal kingdom and the major concern is from mycotoxins group of Aflatoxins, Trichothecenes, Ochratoxins, Ergot alkaloid (Ergolin), Fumonisins, Patulin, and Zearalenone. These seven groups of mycotoxins are capable of causing health hazard for both human and animals, in addition to the economic loss.

General symptoms [3] after direct ingestion (intake) of mycotoxins contaminated foods or indirectly from the ingestion of meats or drinking milk from animals that are fed contaminated animal feeds are fatigue, weakness, headache, light sensitivity, poor memory, difficult word finding, difficulty concentration, morning stiffness, joint pain, unusual skin sensations, tingling, numbness, shortness of breath, sinus congestion, chronic cough, increase urinary frequency, increase thirst, red eyes, blurred vision, sweats, mood swings, abdominal pain, diarrhea, and bloating. These symptoms are in addition, to serious health such as kidney toxicity, immune suppression, autism, neurotoxicity, depression, chronic fatigue syndrome, cancer, acute pulmonary hemorrhage, aplastic anemia, and birth defects. These toxicity symptoms are depend- 
ing on the infected host (human or animal) and the host susceptibility (immunity) [4].

Toxigenic fungi that infect agriculture crops and produce mycotoxins are being classified into two groups. These two groups are: Field (plant) pathogen fungi that infect crops before harvesting, and Storage fungi that infect crops after harvesting [5].

Most common fungal genus of concern that is capable to produce these seven mycotoxins groups are Aspergillus, Fusarium, penicillium, and Claviceps. These mycotoxins contaminate grains, cereals, cereals-based products, oilseeds, milk, milk products, fruits, vegetables, dried fruits, herbs, and spices. Cereal and cereals-based are products of corn, corn gluten meal, wheat, wheat bran, soy bean meal, rice and rice bran. The presence of these mycotoxins in food and feed supplies are major concern, similar to the concern from foodborne pathogens.

Mycotoxins not only causing health hazard or even death to human and animals, but also impact food security and nutrition by reducing the access to safety and healthy foods/animal feeds for both human and animals [6].

Due to the high toxicity of mycotoxins, the level of mycotoxins in grains, foods and feeds must be kept as low as possible, and maximum acceptable (tolerable) of mycotoxins in grains, foods and feeds were established and regulated [7] by the collaboration of World Health Organization (WHO) and Food and Agriculture Organization (FAO). These maximum acceptable level of mycotoxins in grains, foods and feeds are very low in the range of microgram (ug) or part per million (ppm). The main responsibility in comply with mycotoxins regulations to minimize the risk of mycotoxins contamination in food and feed supplies are agriculture crops growers, food processors, retails, and consumers. Following Good Agriculture Practices (GAPs), Good Manufacturing Practices (GMPs), and proper storage protocols for grains, foods, animal feeds, or any other susceptible edible product for mycotoxins contamination are key factors for foods and feeds safety.

\section{Nature and Toxicity of Mycotoxins}

Several hundred of different mycotoxins have been identified, but the main concern is from mycotoxins that are observed to cause severe health hazard for both human and animals. These mycotoxins are: Aflatoxins, Trichothecenes, Ochratoxins, Ergot alkaloid (Ergolin), Fumonisins, Patulin, and Zearalenone (Figure $1)$.

\subsection{Aflatoxins}

Aflatoxins are the major group of mycotoxins due to their wide spread in food and feed supply chains. Aflatoxins are toxic and Carcinogenic chemicals [8] that are produced by the fungal genus Aspergillus especially from the two species of A. flavus and A. parasiticus. These two species of Aspergillus are not plant pa- 
thogens, but are present in soil, contaminating grains and other agriculture crops such, wheat, corn, sorghum, rice, millet, peanut, cotton seed, sesame seed, sunflower seed, and tree nuts that are stored improperly. It is important to highlight that organic crops that are not treated with fungicides are more susceptible to aflatoxins contamination. When these agriculture crops are used as raw materials in foods and animal feeds processing, it contaminates end products causing health hazard for both human and animals.

Farm animals and poultry consumed contaminated feeds with aflatoxins produce contaminated meat, milk, milk products, and eggs with aflatoxin. Human ingestion (intake) of these contaminated food products with aflatoxins may cause, liver damage, cancer, and effecting children growth development. Children are more susceptible to aflatoxins contaminated foods than adult. Adults are susceptible at higher dose [9].

There are more than fourteen chemical structures of aflatoxins that are produced as secondary metabolites by the fungal genus Aspergillus, and the major aflatoxins of concern are Aflatoxin B1, B2, G1, G2, M1, and M2 (Figure 2). From these aflatoxins, the aflatoxin B1 is considered to be the most toxic and potent carcinogen, correlated to liver cancer (liver is the most organ that is susceptible to the toxicity of aflatoxins). In addition, aflatoxin B1 is capable to permeate through skin causing major health risk [10].

Aflatoxins are most commonly ingested fugal metabolites in foods and feeds. To protect the health of human and animals from the toxicity of high dose of aflatoxins, accepted (tolerable) levels of aflatoxins in foods and feeds are in the range of 20 to $300 \mathrm{ppm}$ depends on the product and the host (children, adult, or animals) [11]. These acceptable levels of aflatoxins in foods and feeds are recommended by Food and Drug Administration (FDA) in United States (Figure 3). FDA in United States has the authority to recall any food or animal feed that contains higher level of aflatoxins than the established acceptable limits.

Chemical

Aflatoxins

Trichothecenes

Ochratoxin A

Ergot alkaloids

Fumonisins

Patulin

Zearalenone
Source

Aspergillus flavus and A. parasiticus

Mainly Fusarium

Penicillium verrucosum

A. ochraceus

Claviceps purpurea

Fusarium moniliforme

P. expansum

Fusarium spp
Associated Food

Corn, peanuts, tree nuts, milk

Cereals and other foods

Wheat, barley, corn

Rye, barley, wheat

Corn

Apples, pears

Cereals, oil, starch

Figure 1. The most mycotoxigenic fungal genera are Apsergillus, Penicillium Fusarium, and Calviceps. Producing Aflatoxins, Trichothecenes, Ochratoxins, Ergot alkaloids, Fumononisins, Patulin, and Zearalenone. 
<smiles>COc1cc2c(c3oc(=O)c4c(c13)CCC4=O)C1C=COC1O2</smiles>

Aflatoxin B1<smiles>COc1cc2c(c3oc(=O)c4c(c13)C1CCOC1O4)C(=O)CC2</smiles>

Aflatoxin B2<smiles>COc1cc2c(c3oc(=O)c4c(c13)COC4=O)C1C=COC1OC2</smiles>

Aflatoxin G1<smiles>COc1cc2c(c3oc(=O)c4c(c13)C1CCOC4O1)C(=O)OC2</smiles>

Aflatoxin G2<smiles>COc1cc2c(c3oc(=O)c4c(c13)CCC4=O)C1(O)C=COC1O2</smiles>

Aflatoxin M1<smiles>COc1cc2c(c3oc(=O)c4c(c13)CCC4=O)C1(O)CCOC1O2</smiles>

Aflatoxin M2

Figure 2. Chemical structure of aflatoxins $B_{1}, B_{2}, G_{1}, G_{2}, M_{1}, M_{2}$, the most common one in nature is Aflatoxin $B_{1}$.

\begin{tabular}{|c|c|c|}
\hline Intended Use & $\begin{array}{l}\text { Grain, Grain By-Product, } \\
\text { Feed or other Products }\end{array}$ & $\begin{array}{c}\text { Aflatoxin Level } \\
\text { [parts per billion (p.p.b.)] }\end{array}$ \\
\hline Human consumption & Milk & $\begin{array}{l}0.5 \text { p.p.b. } \\
\text { (aflatoxin M1) }\end{array}$ \\
\hline Human consumption & $\begin{array}{l}\text { Foods, peanuts and peanut } \\
\text { products, brazil and pistachio } \\
\text { nuts }\end{array}$ & 20 p.p.b. \\
\hline Immature animals & $\begin{array}{l}\text { Corn, peanut products, and } \\
\text { other animal feeds and } \\
\text { ingredients, excluding } \\
\text { cottonseed meal }\end{array}$ & 20 p.p.b. \\
\hline $\begin{array}{l}\text { Dairy animals, animals not } \\
\text { listed above, or unknown use }\end{array}$ & $\begin{array}{l}\text { Corn, peanut products, } \\
\text { cottonseed, and other animal } \\
\text { feeds and ingredients }\end{array}$ & 20 p.p.b. \\
\hline $\begin{array}{l}\text { Breeding cattle, breeding } \\
\text { swine and mature poultry }\end{array}$ & Corn and peanut products & 100 p.p.b. \\
\hline $\begin{array}{l}\text { Finishing swine } 100 \text { pounds } \\
\text { or greater in weight }\end{array}$ & Corn and peanut products & 200 p.p.b. \\
\hline $\begin{array}{l}\text { Finishing (i.e., feedlot) beef } \\
\text { cattle }\end{array}$ & Corn and peanut products & 300 p.p.b. \\
\hline $\begin{array}{l}\text { Beef, cattle, swine or poultry, } \\
\text { regardless of age or breeding } \\
\text { status }\end{array}$ & Cottonseed meal & 300 p.p.b. \\
\hline
\end{tabular}

Figure 3. FDA action levels for Aflatoxins present in foods, animal feeds, and food/feed ingredients. FDA Regulatory Guidance for mycotoxins.

\subsection{Trichothecenes}

Trichothecenes family is classified into four types, Type A, B, C, and D. Chemical structure for these four types are belong to sesquiterpene having epoxide ring, and side chains of methyl, and hydroxyl or acetyl group at appropriate positions on the trichothecenes nucleus (Figure 4). These four types of trichothecenes are very stable during food processing such as milling or cooking, and during the storage of contaminated finish products [12].

Trichothecenes family contaminates grains such as wheat, corn, and oat produced from agriculture crops infected with the fungal genus Fusarium, specially 
from the species of F. graminearum, F. sporotrichioides, F. poae, and F. equiseti. In addition to, others species from fungal genus of Trichoderma, Myrothecium, Trichothecium, Cephalosporium, Verticomonosporium, and Stachybotrys that are also, capable to produce trichothecenes. Some of these toxigenic fungi species such as Stachybotrys chartarum is capable to proliferate in damp indoor environment causing environmental health hazard for building occupants [13].

Type A \& B of trichothecenes are the two types with special interest for human and animal health, and type $A$ is more toxic than type $B$ [14].

Type A trichothecene is subclassified into: Don, 3-ADon, 15-ADon, Niv, T-2, HT-2, and 4, 15 Das. All these subclasses have the same trichothecene nucleus but are variable in R1, R2, R3, R4, and R5 side chains (Figure 5). From these Type A subclasses T-2 trichothecene (Figure 6) is highly toxic by inhibiting protein synthesis for both human and animal cells leading into death at toxicity $\mathrm{LD}_{50}$ value about $1 \mathrm{mg} / \mathrm{kg}$ body weight [15]. In addition, dermal exposer to subclass T-2 trichothecene lead to skin burning pain, redness, and blisters. In the case of T-2 trichothecene oral ingestion lead to vomiting, diarrhea and might result in blurred vision, nasal irritation, and cough [16]. Because of the high toxicity of T-2 trichothecene it is manufactured by fermentation from industrial strain of Fusarium sp. for the use in biological warfare [17].

Subclass HT-2 trichothecene (Figure 6) is also, strong protein synthesis inhibition, and the host could suffer from acute toxicity, gastrointestinal irritation, and high incidence of para-esophageal and stomach ulcers [18]. The estimated toxicity $\mathrm{LD}_{50}$ value about $12-34 \mathrm{ng} / \mathrm{kg}$ body weight for both T-2 and HT-2 trichothecenes as established by the European Food Safety Authorities.

Type B trichothecene is subclassified into Deoxynivalenol (Don), Nivalenol, Trichothecin, and Fusrenon-x. All have the same trichothecenes nucleus but are variable in R1, R2, R3, and R4 side chains (Figure 7). The most common one from Type $B$ trichothecene is the deoxynivalenol that is also known by the name vomitoxin (Figure 8). Deoxynivalenol is primary produced from $F$. graminearum, and $F$. culmorusis that contaminate wheat, barley, oats, rye, and corn. These two Fusarium species, are plant pathogens causing plant diseases such as fusarium head blight in wheat, and fusarium ear blight in corn [19].

A

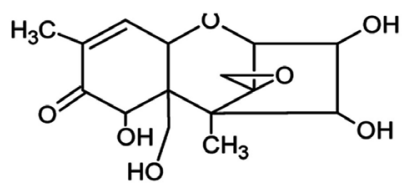

C

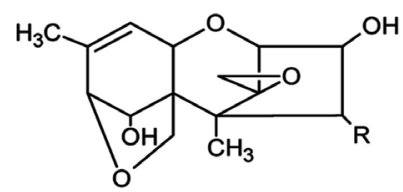

B

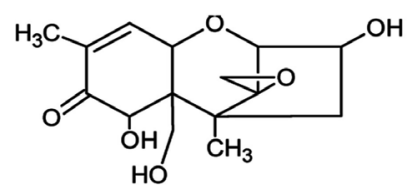

D

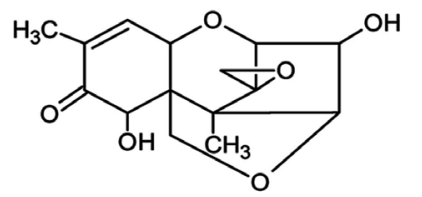

Figure 4. Trichothecenes are very large family of Type A, Type B, and Type, C. All with chemical structure belong to sesquiterpene chemical structure. Trichothecenes family is produced by various species of Fusarium and by other fungal genera. 


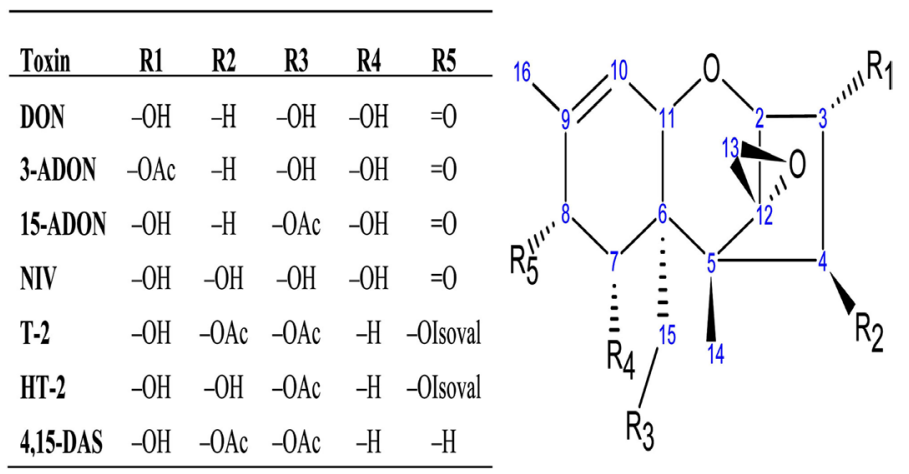

Figure 5. Trichothecenes Type A are DON, 3-ADON. 15-ADON, NIV, T-2, HT-2, and 4,15-DAS. All trichothecenes type A have the same trichothecene nucleus but are vary in R1, R2, R3, R4, and R5 side chains.

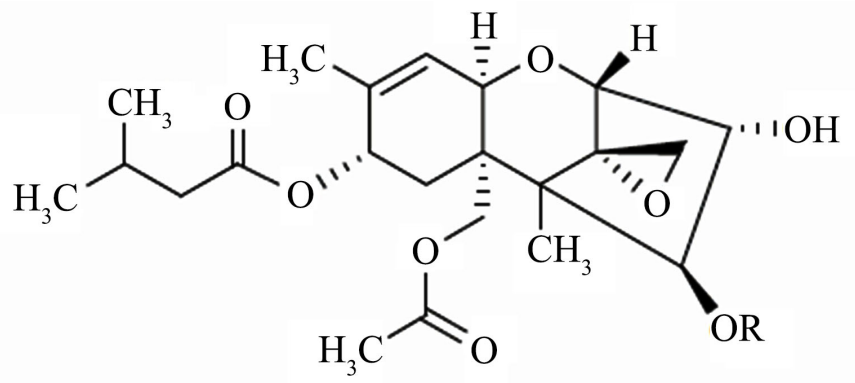

$\mathrm{T}-2$ Toxin: $\mathrm{R}=\mathrm{Ac}$ HT-2 Toxin: $\mathrm{R}=\mathrm{H}$

Figure 6. Mycotoxin T-2 and HT-2 are belong to trichothecenes Type A, have the same chemical structure, but variable in the OR side chain.

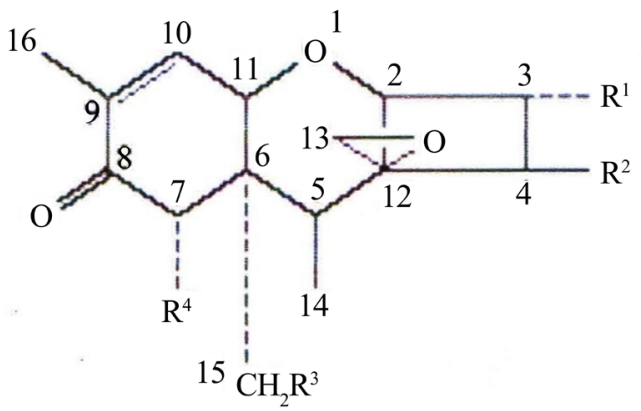

$\begin{array}{ccccc}\text { Trichothecenes } & \text { R1 } & \underline{\mathbf{R 2}} & \underline{\mathbf{R} 3} & \underline{\mathbf{R}} \\ \text { Deoxynivalenol } & \mathrm{OH} & \mathrm{H} & \mathrm{OH} & \mathrm{OH} \\ \text { Nivilenol } & \mathrm{OH} & \mathrm{OH} & \mathrm{OH} & \mathrm{OH} \\ \text { Trichothecin } & \mathrm{H} & \mathrm{OCOCH}=\mathrm{HCHCH} 3 & \mathrm{H} & \mathrm{H} \\ \text { Fusorinon-X } & \mathrm{OH} & \mathrm{OAC} & \mathrm{OH} & \mathrm{OH}\end{array}$

Figure 7. Trichothecenes Type B are Deoxynivalenol, Nivalenol, Trichothecin, and Fusorenon-X. All have the same trichothecene nucleus but variable in R1, R2, R3, and R4, side chains. 


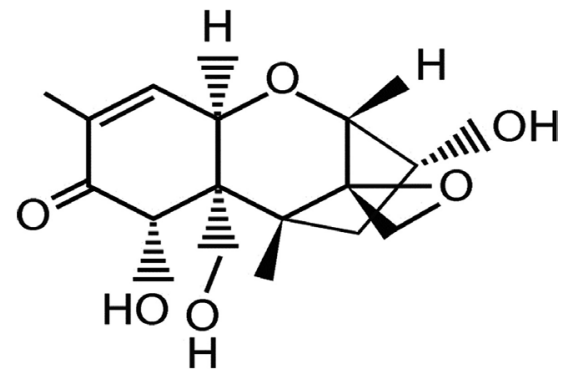

Figure 8. Chemical structure of the mycotoxin Deoxynivalenol (Don) also known by the name Vomitoxin. It is belonging to trichothecenes Type B.

Food and Drug Administration (FDA) in United States established acceptable daily intake (ADI) of all trichothecenes family to the maximum level of $1 \mathrm{ppm}$ for human, $10 \mathrm{ppm}$ for cattle, and $2 \mathrm{ppm}$ for dairy cow. It is observed that animals fed grains contaminated with trichothecenes above the acceptable level showed refusal to fed and weight loss.

\subsection{Ochratoxins}

Ochratoxins family is classified into three Types A, B, and C. These three types have the same ochratoxin nucleus but vary in R side chains (Figure 9). Ochratoxin A (OTA) is commonly detected and the most toxic one comparing to other ochratoxins types [20].

Ochratoxins family is produced by different species from the two fungal genuses of Aspergillus and Penicillium, especially from the species of $A$. ochranceus, $A$. niger, $A$. carbonarium, and $P$. verrucous. The fungi $A$. ochranceus is commonly proliferate and produce ochratoxins on wine grapes and grain crops that can be detected in wine and beer manufactured from these contaminated wine grapes, and grains respectively [21].

The common ochratoxin A (Figure 10) is moderately stable and mainly presence in grains (wheat, barley, and rye), cereals, coffee, dried grapes, wine, beer and meat products [22]. In addition, ochratoxin A is frequently contaminate water and house heating ducts [23] causing environmental health hazard for both human and animals.

Ochratoxin A can be detected in host tissues, organs, blood, and breast milk from human and animals ingested contaminated food or feed with this ochratoxin, plus causing nephrotoxicity and renal tumors for both human and animals [24].

Ochratoxin A estimated acceptable daily intake is in the range of $5 \mathrm{ng} / \mathrm{kg}$ body weight. Codex Committee of Food additives and Contaminants (CCFAC) set the maximum acceptable level of Ochratoxin A in foods and animal feeds to a level that should not exceed $5 \mu \mathrm{g} / \mathrm{kg}$ food or feed [25]. In general, laboratory analysis for the detection and quantification of Ochratoxin A in food and feed products demonstrated that majority of marketed products contains below the standard acceptable level of $5 \mathrm{ug} / \mathrm{kg}$ food or feed. 
<smiles>C[C@@H]1Cc2c(Cl)cc(C(=O)N[C@@H](Cc3ccccc3)C(=O)O)c(O)c2C(=O)O1</smiles>

Ochratoxin A<smiles>C[C@@H]1Cc2ccc(C(=O)N[C@@H](Cc3ccccc3)C(=O)O)c(O)c2C(=O)O1</smiles>

Ochratoxin B<smiles>CCOC(=O)[C@H](Cc1ccccc1)NC(=O)c1cc(Cl)c2c(c1C)C(=O)O[C@@H](C)C2</smiles>

Ochratoxin C

Figure 9. Ochratoxin A (OT-A), Ochratoxin B (OT-B), and Ochratoxin C (OT-C) are phenylalanine derivatives with the chemical structure: $\mathrm{C}_{20} \mathrm{H}_{18} \mathrm{ClNO}_{6}$ for (OT-A), $\mathrm{C}_{20} \mathrm{H}_{19} \mathrm{ClNO}_{6}$ for (OT-B), and $\mathrm{C}_{22} \mathrm{H}_{22} \mathrm{ClNO}_{6}$ for (OT-C).<smiles>C[C@@H]1Cc2c(Cl)cc(C(=O)N[C@@H](Cc3ccccc3)C(=O)O)c(O)c2C(=O)O1</smiles>

Figure 10. Ochratoxin A (OT-A) is a phenylalanine derivative structurally consist of a para-chlorophenol group containing a dihydroisocoumarin moiety that is amide-linked to L-phenylalanine.

\subsection{Ergot Alkaloids}

Ergot alkaloids are large family of chemical compounds that are produced by fungal plant pathogen effecting a wide variety of grass species, and grain crops. This fungal plant pathogen is from the genus Claviceps that are capable to produce sclerotia in several grass species. Sclerotia (Figure 11) is multicellular fungi structure with regular morphology as reproductive bodied that are able to survive in the time of fungi dormant stage [26]. The major species from this fungal 
genus Claviceps that infect grain crops and produce the mycotoxin ergot alkaloids in grains are $C$. purpurea, $C$. fusiformis, and $C$. paspali.

Chemical structure of ergot alkaloids produced by Claviceps species are indole derivatives (Figure 12), with severe toxic effect for both human and animals. The toxic effect of ergot alkaloids is known by the name ergotism [27], and there are two types of ergotism symptoms. These two symptoms are; Gangrenous that effects vascular system, and Convulsive that effects central nervous system causing hallucinations. Modern technology in grains mechanical cleaning successfully reduced human ergotism disease, but these ergotism diseases are still veterinary concern [28].

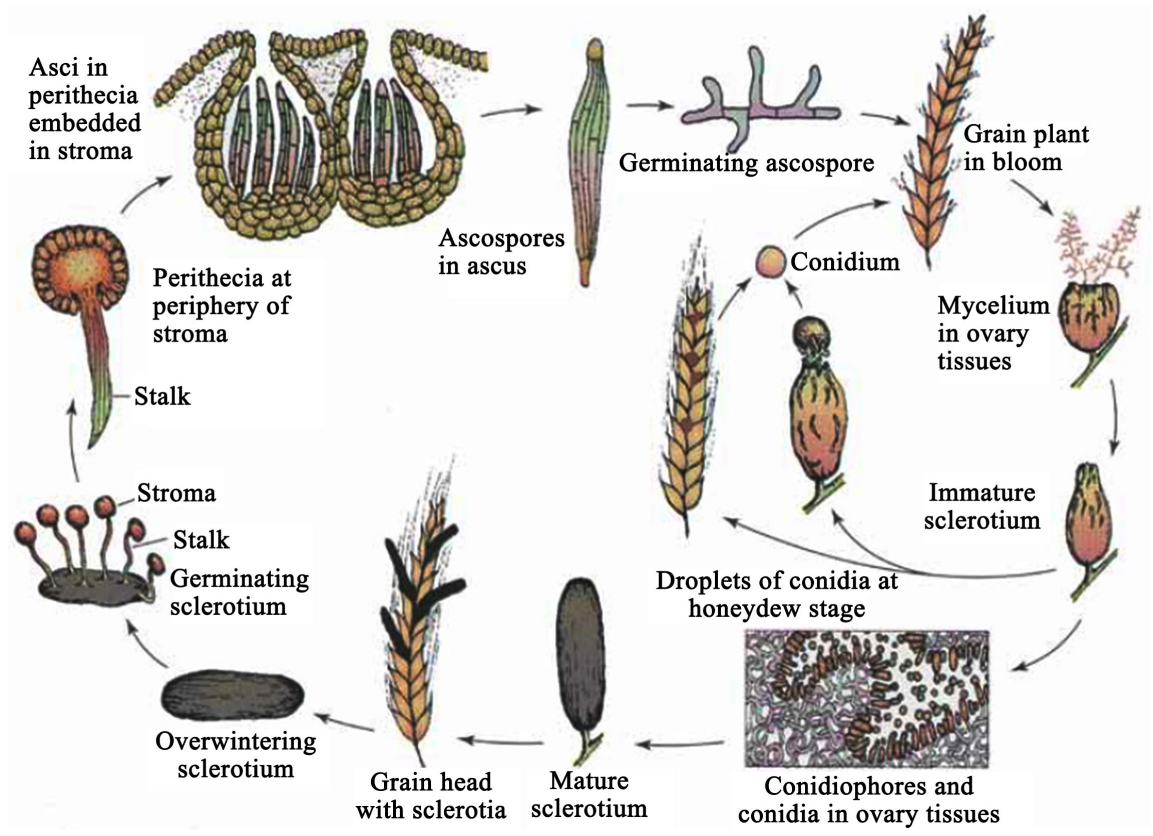

Figure 11. Mature Sclerotia of Claviceps ergot in infected grain crops or grasses germinate in the spring, prior the flowering and give rise to a stroma (stromata plural), where sexual reproduction is occurred for the production of Ascospores. Ergot of Rye, 2019 The American Phytopathological Society. By: Gail L. Schumann and Sai SreeUppala.

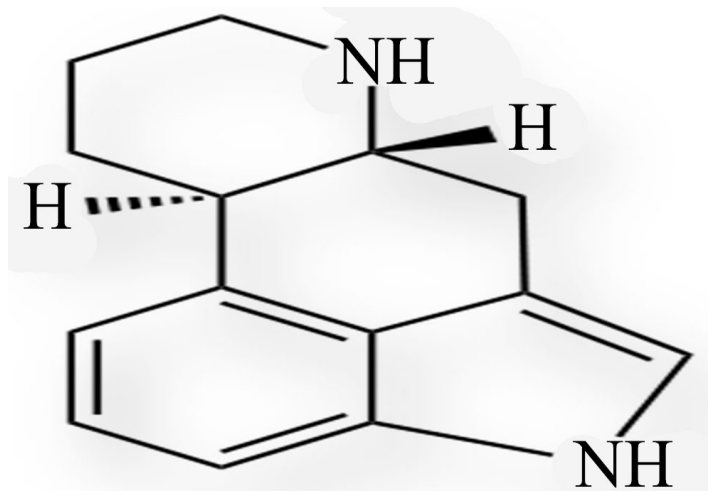

Figure 12. Chemical structure of ergot alkaloids $\mathrm{C}_{14} \mathrm{H}_{18} \mathrm{~N}_{2}$ is classified among the indole alkaloids and is derived from the tetracycline ergoline. 
Ergotism is a worldwide farm animals' disease for cattle, pigs, and sheep resulted mainly from the ingestion of sclerotia of the fungus $C$. purpurea and from other Claviceps species, in replacement to mycotoxin contaminated grains. Sclerotia from the fungus $C$. purpurea contains the highest concentration of the mycotoxin ergot alkaloids comparing to other Claviceps species.

Ergotism symptoms in farm animals can be observed after animals grazed infected seed heads, or after fed contaminated grains. The concentration of 200 ppm of ergot alkaloids in grains is enough to cause clinical symptoms in farm animals, and farm animal with ergotism symptoms can cause sporadic outbreaks to other animal species that are susceptible to this mycotoxin of ergot alkaloids [29]. The simple diagnosis of ergotism in farm animals is based on just observing the ergotism symptoms on the animal, or by the detection of ergot sclerotia (reproductive body of fungus genus Claviceps) in grains or hays.

Acceptable limits of ergot alkaloids in cereals, and grains have been established by Food and Agriculture Organization (FAO) to $0-0.05 \mathrm{ppm}$ in cereal or grains for human consumption, and less than $0.3 \mathrm{ppm}$ in grains for animal feeds [30]. These established standard acceptable limits of ergot alkaloids in grains used for foods and animal feeds production are being applied in European Union, and United States. It is important to highlight that grains contaminated with above these established limits are banned from entering food or feed chains.

Finally, there are some pharmaceutical benefits from the mycotoxin ergot alkaloids. There are numerous semisynthetic derivatives of the ergot alkaloids that are used as therapeutic pharmaceutical drugs and marketed by pharmaceutical industries [31]. These marketed pharmaceutical drugs of semisynthetic derivatives from the ergot alkaloids are Dihydroergotamine and ergotamine used for the treatment and the alleviation of migraines. Other semisynthetic derivatives from ergot alkaloids are Lisuride used for managing Parkinson's disease, and Methylergometrine used for the prevention and control excessive bleeding following vaginal childbirth. Ergot alkaloids are manufactured as a precursor for the production of these semisynthetic derivatives of pharmaceutical drugs by fermentation using industrial strains of $C$. purpurea [32].

\subsection{Fumonisins}

Fumonisins family is group of mycotoxins mainly produced by two species from the fungal genus Fusarium. These species are F. verticilloides, and F. proliferatum, both are fungal plant pathogens infect corn in the field, and in storage stage. These two Fusarium species causing corn disease known by the name fusarium ear rot [33].

There are more than ten types of the mycotoxin fumonisins that have been identified and characterized. The common ones are fumonisin $\mathrm{B}_{1}\left(\mathrm{FB}_{1}\right)$, fumonisin $\mathrm{B}_{2}\left(\mathrm{FB}_{2}\right)$, fumonisin $\mathrm{B}_{3}\left(\mathrm{FB}_{3}\right)$, fumonisin $\mathrm{C}_{1}\left(\mathrm{FC}_{1}\right)$, fumonisin $\mathrm{C}_{3}\left(\mathrm{FC}_{3}\right)$, and fumonisin $\mathrm{C}_{4}\left(\mathrm{FC}_{4}\right)$ (Figure 13). From these mycotoxins, fumonisin $\mathrm{B}_{1}\left(\mathrm{FB}_{1}\right)$ is the major one that invades corn, causing economical losses [34]. 


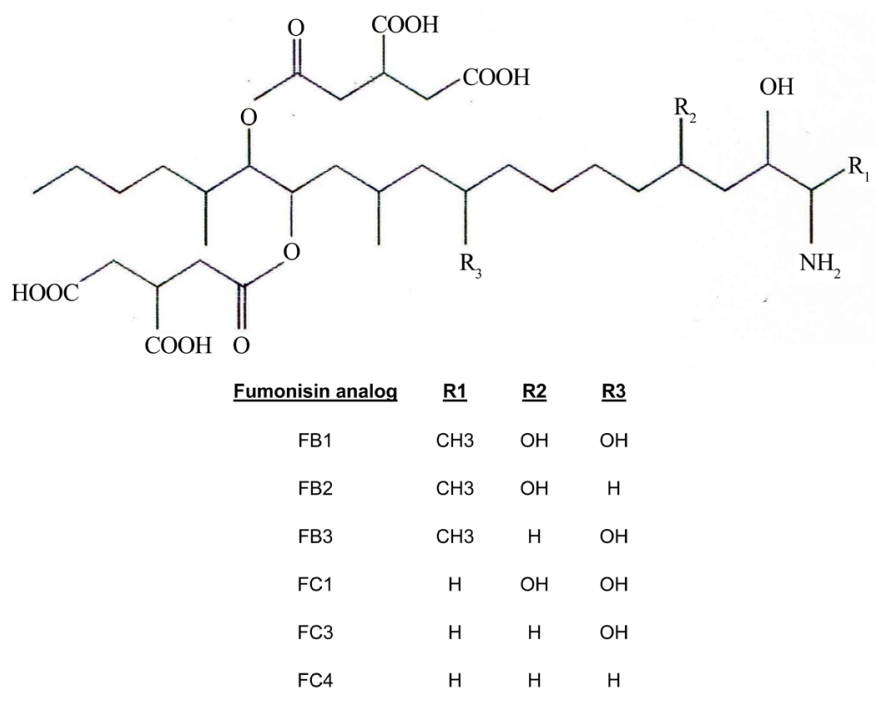

Figure 13. Fumonisin analog of $\mathrm{FB}_{1}, \mathrm{FB}_{2}, \mathrm{FB}_{3}, \mathrm{FB}_{4}, \mathrm{FC}_{1}, \mathrm{FC}_{3}$, and $\mathrm{FC}_{4}$. are chemical structurally related mycotoxins with variable R1, R2, R3 side chains.

The detected levels of $\mathrm{FB}_{1}$ in contaminated corn is varies based on geographic location and field environmental conditions such as, temperature, humidity, drought, and susceptibility of planted corn to insect's damage. In addition, storage practice of corn, and corn products plays an important factor in the Fusarium species invasion, and the production of mycotoxin $\mathrm{FB}_{1}$.

Fumonisins family was discovered in the late 1980, as a result of epidemiology studies regarding the causes of esophageal cancer in Africa [35]. In these studies, it was discovered that mycotoxin fumonisins produced by the fungal genus $\mathrm{Fu}$ sarium, especially from the two species of $F$. verticilloides, and $F$. proliferatum are responsible in causing esophageal cancer to human.

Fumonisins family is highly toxic to animals, especially for horses and swine causing a variety of adverse effects. Horses ingested contaminated corn with fumonisins may develop a fatal disease known by the name equine leukoencephalomalacia with symptoms including drowsiness, blindness staggering, and liquification of brain tissue [36]. Swine ingested contaminated corn with fumonisins experiences loss apatite's, weight loss, liver damage, and may develop a pulmonary edema. Pulmonary edema is fatal disease to swine due to the accumulation of fluid in the lung [37].

The accepted daily intake of $\mathrm{FB}_{1}, \mathrm{FB}_{2}, \mathrm{FB}_{3}$, alone or in combination in contaminated foods or feeds is in the range of $2 \mathrm{ug} / \mathrm{kg}$ body weight. Food and Drug Administration (FDA) in Unites States recommended that maximum acceptable levels of fumonisins in human foods should not exceed $4 \mathrm{ppm} / \mathrm{kg}$, and in animal feeds should not exceed $5-100 \mathrm{ppm} / \mathrm{kg}$ [38]. These wide ranges of acceptable levels of fumonisins in the range from $5-100 \mathrm{ppm} / \mathrm{kg}$ animal feeds are depending on the type of farm animal. As an example, the recommend acceptable limit of fumonisins in horses feed is $5 \mathrm{ppm} / \mathrm{kg}$, for pigs feed is $10 \mathrm{ppm} / \mathrm{kg}$, and for poultry feed is $100 \mathrm{ppm} / \mathrm{kg}$. These established acceptable limits of fumonisins for 
both human foods and animals' feeds can be achieved by the application of Good Agriculture Practices (AGPs), and Good Manufacture practices (GMPs).

\subsection{Patulin}

Patulin is a mycotoxin produced by a variety of fungi, mainly from fungal genus of Aspergillus, Penicillium, and Paecilomyces. From these patulin producing fungi, the fungal species of Penicillium expansum is commonly occurs in rotten apples. This fungus of Penicillium expansum is a plant pathogen that invades apple, pear, cherry, and other fruits, causing a disease known by the name blue mold [39]. Analytical assay of Patulin in apples are commonly used to measure the quality of apples used for the production of apple cider juice. Patulin is commonly non-detectable in fermented apple juice by yeast strains of Saccharomyces cerevisiae used for the production of alcohol beverage, this is due to the degradation (detoxification) of patulin by yeast strains in fermentation process [40]. It is important to highlight that Patulin is also detectable in rotten vegetables.

Patulin is an organic chemical compound has a lactone structure and is classified as polyketide (Figure 14). Its chemical structure of 4-hydroxyly- $4 \mathrm{H}$-furo [3,2-clypran-2 (6H)-one], is carcinogenic when injected intradermally into mice, and some research data suggested that is non-carcinogenic when administered orally.

Several clinical studies demonstrated that the ingestion of patulin in fresh fruits or juices is associated with symptoms such as gastrointestinal, immunological, and neurological disease for human [41]. The only know symptom in farm animals from the ingestion of contaminated animal feeds with patulin is hemorrhaging in digestive tract for cattle. In addition, some research studies suggested that patulin is carcinogenic for farm animals as well [42].

This potential carcinogenic property of Patulin, causing concern to food processors and public health authorities, due to the detection of patulin in commercial apple, apple products and apple juice. This concern, leads many countries to regulate the acceptable limits of patulin, into $50 \mu \mathrm{g} / \mathrm{kg}$ in all fruit juice, $25 \mu \mathrm{g} / \mathrm{kg}$ for direct consumption of solid apples, and $10 \mu \mathrm{g} / \mathrm{kg}$ for children's apple products including apple juices [43].

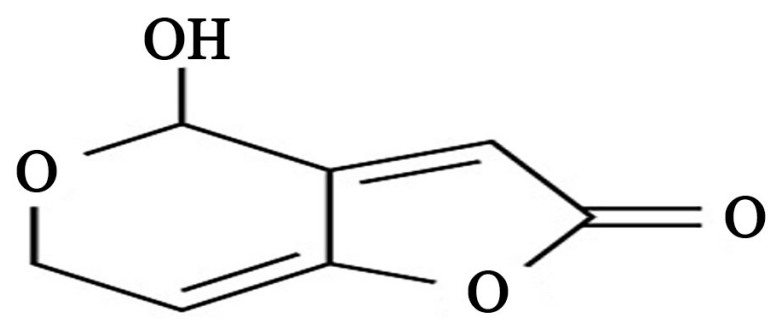

Figure 14. Mycotoxin Patulin $\mathrm{C}_{7} \mathrm{H}_{6} \mathrm{O}_{4}$ is organic chemical compound has a lactone structure and is classified as polyketide with chemical structure of 4-hydroxyly-4H-furo [3,2-clypran-2 (6H)-one]. 


\subsection{Zearalenone}

Zearalenone is a mycotoxin produced by the fungal genus Fusarium, from the same species of $F$. graminearum that produce the mycotoxin deoxynivalenol (trichothecenes type-B subclass). High humidity and low temperature are the optimum conditions that accelerating the proliferation of $F$. graminearum, for the production of zearalenone in corn and other grains crops. Due to the heat stability of Zearalenone, it can be detected in cereals produced from contaminated grain crops such as corn, barely, wheat, rice, oats, and sorghum.

Zearalenone chemicals structure (Figure 15) is a macrocyclic $\beta$-resorcyclic acid lactone, mimicking the productive hormone estrogen [44]. This similarity to estrogen chemical structure is a health risk for both females and males. Zearalenone has been implicated as the cause of female reproductive changes due to its powerful estrogenic activity [45]. In the case of males, estrogenic effects of Zearalenone are causing reduction of libido. Zearalenone may cause other symptoms such as immunosuppression [46]. In the case of animals, hyper estrogenic symptoms of zearalenone have been reported in both laboratory and domestic animals. It is reported that pigs, cattle, sheep, and poultry are susceptible to contaminated feeds with zearalenone, and pigs are the most commonly effected farm animal by zearalenone [47].

Clinical research studies demonstrated effects of zearalenone or its metabolites (Figure 16) on both human and animals including symptoms such as an enlarge uterus, swelling of vulva and vagina (a symptom known by the name vulvovaginitis), enlarged mammary glands, anestrus in the period of fertility, and abortion. In addition, there is clinical evidence demonstrated that zearalenone and its metabolites in contaminated animal feeds could passes these symptoms into nursing piglets through the mother's milk. In general, animal feeds contaminated with zearalenone or its metabolites, frequently causing reproduction disorder to farm animals causing agriculture economical losses [48].

Zearalenone is a stable mycotoxin during grains storage, and in food processing such milling and cooking. Health concern from zearalenone stability and estrogenic activity, resulted in establishing the maximum accepted level of zearalenone to $20 \mu \mathrm{g} / \mathrm{kg}$ in food intended for babies and infants. Plus, joint expert committee on Food Additives of FDA/WHO organizations established the maximum acceptable daily intake of zearalenone in foods or animal feeds to a limit that should not exceed $0.5 \mu \mathrm{g} / \mathrm{kg}$ body weight [49].

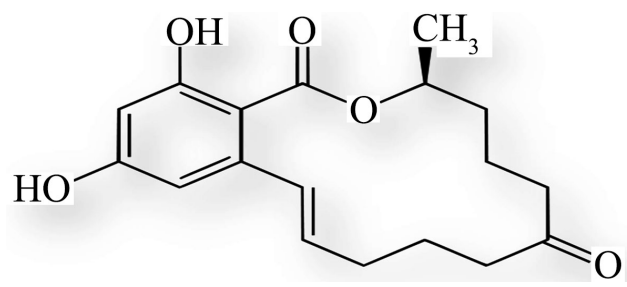

Figure 15. Mycotoxin zearalenone $\mathrm{C}_{18} \mathrm{H}_{22} \mathrm{O}_{5}$ has similar structure to estradiol, it is macrocyclic $\beta$-resorcyclic acid lactone, mimicking the productive hormone estrogen. 
<smiles>C[C@@H]1CCCC(=O)CCC/C=C/c2cc(O)[15cH][13c](O)c2C1=O</smiles>

Zearalenone (ZEN)<smiles>C[C@H]1CCCC(=O)CCCCCc2cc(O)cc(O)c2C(=O)O1</smiles>

Zearalenone (ZAN)<smiles>C[C@H]1CCC[C@H](O)CCC/C=C/c2cc(O)cc(O)c2C(=O)O1</smiles>

$\alpha$-zearalenol $(\alpha-\mathrm{ZOL})$<smiles>C[C@H]1CCC[C@@H](O)CCC/C=C/c2cc(O)cc(O)c2C(=O)O1</smiles>

$\beta$-zearalenol ( $\beta$-ZOL)

Figure 16. Mycotoxin Zearalenone (ZEN) is rapidly metabolized in the intestine into $\alpha$-Zearalenol ( $\alpha$-ZOL), $\beta$-Zearalenol ( $\beta$-ZOL), Zearalenone (ZAN), $\alpha$-zearalanol ( $\alpha$-ZAL), and $\beta$-Zearalanol ( $\beta$-ZAL). All these metabolites have mycotoxin activity.

Due to agriculture economic concern for potential infection of grains crops with Fusarium species and the contamination of harvested grains with zearalenone, several protocols in agriculture fields have been developed to protect grain crops from the infection by the plant pathogen of Fusarium species [50].

\section{Detection Methods of Mycotoxins}

Fungal plant pathogens are spore former microorganisms, at the optimum humidity and temperature conditions fungal spores germinate into vegetative state (mycelium). These mycelia consume nutrient from plant cells to proliferate and produce (secrete) extremely small quantities of secondary metabolites (mycotoxins) that are harmful for both human and animals after the ingestion of contaminated, grains, foods, and animal feeds contaminated with mycotoxins.

The first aim in testing grains, foods or feeds is microscopic examination for the detection of toxigenic fungi (fungi producing mycotoxins). The absence of these toxigenic fungi in test samples is more likely that mycotoxins are not presence in this preliminary testing [51]. Quantitative detection of mycotoxins in grains, foods, or feeds require sophisticated sampling preparation, extraction, cleanup, and quantitative mycotoxins assay with sensitive analytical methods using laboratory instruments.

Extraction from solid samples like grains or cereals can be performed with polar solvents including water. These solvents are also efficient for liquid sample extraction. For quantitative mycotoxins assay, the extract must go through cleanup step to remove co-extracted materials (impurities) that might interfere in mycotoxins assay.

Immune affinity column kits are widely validated and used for extracted samples cleanup especially for mycotoxins assay methods of aflatoxin, ochratoxin A, and fumonisins [52]. The column that contain antibodies specific for given mycotoxin is activated by buffer solution, extracted sample is added into column, 
the mycotoxin if present in the extract will bind to the specific antibodies, unbound (free) impurities can be removed by water or aqueous solution, and the mycotoxin that is bound to its specific antibodies is eluted from the column by a solvent such as methanol.

High performance Liquid Chromatography (HPLC), and Gas Chromatography/Mass spectrometry (GC/MS) are the two wildly used for mycotoxins detection and quantitative assay. High performance Liquid Chromatography (HPLC) separates a mixture of chemical compounds on a stationary column by using carrier solvent such as methanol, or acetonitrile. Separated mycotoxins can be detected and quantified in cleaned extracted sample as passing through a specific detector [53]. Gas Chromatography/Mass spectrometry (GC/MS) separates a mixture of chemical compounds on a stationary column by using a carrier gas such as helium. Separated mycotoxins are detected and quantified in cleaned extracted samples using a mass spectrometer.

These two HPLC and GC/MS assay methods required expensive instruments and technical support, but are very precise and offer a detection limit of less than $0.05 \mathrm{ppm}$.

Currently, a new method of Enzyme-Linked Immuno-Sorbent Assay (ELISA) are developed and commonly used for mycotoxins detection and quantitative assay. A number of commercially available ELISA test kits methods are available for the assay of aflatoxins, deoxynivalenol, fumonisins, ochratoxins, and zearalenone [54]. ELISA methods are plate-based assay method of 96 well that are designed for the detection and quantifying substances such as mycotoxins.

Several ELLISA test methods are available, and one of these methods is a competitive assay method, which a mycotoxin in a sample is competing with known concentration of the same mycotoxin labeled with conjugated enzyme for a limited number of the specific antibody-binding site in the well. The presence of mycotoxin in the test sample is usually measured by the presence or the absence of color. The high mycotoxin (unlabeled) present in the test sample the less color measured. These available ELISA methods are affordable and are rapid in mycotoxins detection. Detection limits of mycotoxins by these ELISA methods are in the range of $0.2 \mathrm{ppm}$, and confirmatory test by HPLC, or GC/MS might be required in the case if lower mycotoxin acceptable limits in grains, foods or feeds are below ELISA detection limit of $0.2 \mathrm{ppm}$.

\section{Prevention and Control Mycotoxins in Foods and Feeds}

Mycotoxins producing fungi might infect (invade) agriculture crops at pre-harvesting time, during harvesting time, and storage. The presence of fungi spores in these agriculture processes are the main cause of fungal proliferation and mycotoxins production. Prevention of fungal invasion, proliferation, and mycotoxins production in pre or post agriculture cops harvesting, and storage are a big task that required understating optimum conditions that enhance the proliferation of fungal infection, and understanding agriculture crops environ- 
mental conditions, plus developing treatment methods to inhibit fungal proliferation and mycotoxins production in agriculture crops and grains storage for the use in foods/animal feeds products.

The inhibition of fungal proliferation in agriculture crops in the pre-harvesting time can be achieved by developing fungal resistant varieties for susceptible agriculture crops [55], developing field management protocols (plant protection) by periodically field inspection, and using approved fungicides or biological control methods if necessary [56].

Inhibition of fungal proliferation in post-harvest grains can be achieved by grains storage in dry conditions (fungi can't proliferate or produce mycotoxins in dried grain at water activity below 0.7 ), and by avoiding grains damage or insects' infestation to protect grains from fungal invasion. Using proper grains storage conditions such as well-designed dry floor storage structure impermeable to moisture is very effective. The most effective grains storage structure but highly costly system is to control insect infestation and fungal proliferation in a sealed storage under modified atmosphere [57].

\section{Decontamination and Detoxification of Mycotoxins}

Grains, foods and animal feeds sometimes required decontamination and chemical detoxification in the case if preventive measures are not able to avoid contamination by mycotoxins to the target acceptable limits. Developing successful decontamination and detoxification are depends on the degree of contamination and the concentration of mycotoxins in grains, foods, or feeds. Physical methods for mycotoxins decontamination such as mechanical separation, cleaning, washing, dehulling, polishing, and heat treatment are acceptable methods, and are currently used with successful results depending on the initial degree of contamination [58].

Different chemical extraction methods have been evaluated on bench scale for detoxification of mycotoxins contaminated grains, foods and animal feeds. Only ammonia treatment for the detoxification of aflatoxin from contaminated grains has been accepted [59]. Biological treatments by using free enzymes or microbial producing enzymes for mycotoxins degradation or bioconversion into nontoxic without losing nutritional value of grains, foods or animal feeds were evaluated on bench scale [60]. These biological methods for mycotoxins detoxification from grains, foods and animals feed showed promising results, but none of these biological treatments have been approved for large scale operations by world health organization.

\section{Regulatory Guidance for Mycotoxins}

The discovery of Aflatoxins in the early 1960s and understanding health hazards of mycotoxins to human and animals, was the driving force for worldwide health organizations to became active in establishing mycotoxins regulations to protect human and animals from harmful effects of mycotoxins that might contaminate 
grains. cereals, foods and animal feeds [61]. There are multiple factors played important decisions in establishing mycotoxins regulations and acceptable (tolerable) limits in grains, foods, and animal feeds. These factors include the toxicity for each mycotoxin, and the accuracy in assay methods, in addition to political reasons for each country such as economic and commercial interest.

As an example, regulatory and enforcement framework that was issued in United Stated by Food and Drugs Administration (FDA) for aflatoxin, deoxynivalenol, and fumonisins in raw grains, foods and animal feeds, were established in the following forms:

- Advisory levels: Provide guidance concerning level for each mycotoxin present in grains, foods or animal feeds that the agency believed to provide food safety and protection for both human and animals.

- Action level: Develop standard level for each mycotoxin contamination in grains, foods, and animal feeds at which the agency is prepared to take regulatory action.

- Regulatory limit: Issues regulatory limits for each mycotoxin presence in grains, foods, and animal feeds that are acceptable by the agency.

It is important to highlight that the policy and guidance that was set by Food and drugs Administration (FDA) in United States does not permit blending foods or animal feeds containing unacceptable limit of mycotoxins with uncontaminated foods or animal feeds as a way to reduce mycotoxin content to the acceptable limit. In addition, FDA reserve the right to take enforcement action including seizer any grains, food or animal feed that exceed the acceptable limit established by the agency for each mycotoxin.

World Food and Nutrition Division in the United Nation Food and Agriculture Organization (FAO), reported that there are at least 77 countries have been developed specific regulations for mycotoxins in grains, foods, and animal feeds, but the developed specific regulations for each country showed diversity specially in mycotoxins acceptable limits. These diversities were the reason for the need in developing a worldwide harmonization for mycotoxins regulations and acceptable limits. Codex Alimentarius Commissions (CAC), with the support of Food and Agriculture Organization (FAO), and World Health Organization (WHO) carried the responsibility for mycotoxins acceptable limits worldwide harmonization. The current developed harmonization of mycotoxins regulations and acceptable limits will improve international trades, and the safety of imported foods and animal feeds products for both human and animals' consumption, plus, it will have positive impacts on the world economy.

International regulations of mycotoxins in grains, foods and animal feeds were published in years from 1980s to 1990s. These published international regulations covered sampling protocols, standard mycotoxins assay methods, acceptable limits of each mycotoxin in grains, foods, and animal feed, acceptable (tolerable) daily intake of each mycotoxin for both human and animals, and governments authorities in enforcing these established mycotoxins regulations, 
and accepted limits.

\section{Discussion}

Mycotoxin is a term that was introduced in 1960s after the discovery in United Kingdom (UK) a toxin in animal feed containing peanuts causing turkey's death. The toxin was isolated and identified to be aflatoxin $B_{1}$ produced by the fungi Aspergillus flavus. Other mycotoxins were identified later.

Mycotoxins are secondary metabolites produced by the kingdom of fungi, and was identified by Bennett [62] as "natural products produced by fungi that evoke a toxic response when introduces in lower concentrations to higher vertebrates and other animals by a natural route". Mycotoxins are not essential for fungal proliferation (growth), and the reason for the production of mycotoxins by these toxigenic fungi as secondary metabolites is still scientifically unknown. Most mycotoxins of concerns are produced by five fungus genera of Aspergillus, Penicillium, Fusarium, Claviceps, and Paecilomyces. These five fungus genera and species infect and contaminate agriculture crops, foods and animal feeds, and under optimum conditions of humidity and temperature proliferate and produce mycotoxins.

Mycotoxins produced by these fungus genera species are Aflatoxins, Trichothesenese, Ochratoxins, Ergot alkaloid (Ergolin), Fumonisin, Patulin, and Zearalenone. Health effects from these mycotoxins depend on the nature of mycotoxin, concentration, length of exposure, age, sex, and the host defense mechanism. General symptoms of illnesses after the ingestion of mycotoxins are associated with both acute (single exposure) or chronic (multiple exposure) causing severe neurological, immunological, and gastrointestinal illness, plus, could induce cancer and immune deficiency.

Toxigenic fungi that produce mycotoxins may infect or contaminate agriculture crops at pre-harvest, harvesting time, post-harvest, and during storage causing a significant economic impact on agriculture economy, especially for agriculture commodities of corn, wheat, peanuts, other nuts, cottonseed, and coffee, with estimated annual losses about one billion tons [63]. This agriculture economic loss from mycotoxins is in addition to the health risk for both human and animals.

Traditionally, these toxigenic fungi that contaminate agriculture crops are divided into two classes: 1) Field fungi such as plant pathogens of Fusarium species that infect grain seed crops during plant growth. 2) Storage fungi such as non-plant pathogens of Aspergillus species, and Penicillium species that proliferate during grains storage. There are too many factors that are involved for these toxigenic fungi to proliferate and produce mycotoxins. These factors are agriculture crops susceptibility to fungi infection, optimum conditions of temperature climate, optimum moisture content in infected grains, and physical grains damage due to insect's infestation.

Prevention of fungal infection and proliferation in agriculture crops is very 
important factor in preventing mycotoxins production that contaminates grains, foods and animal feeds. The first step in prevention is the inhibition of fungal proliferation for the production of mycotoxins. This first stage of prevention can be achieved by the application of several technologies and practices such as developing fungal resistant crops varieties, control fungal infection or contamination via the application of proper Good Agriculture Practices (GAPs) in the field, lowering moisture content and temperature of post harvested grains during storage, applied fungicides to inhibit fungal proliferation, applied insecticides to control insects infestation, and the proper application of Good Manufacture Practices (GMPs) in foods/animal feeds manufacturing.

Mycotoxins regulations have been established in many countries after the discovery of the mycotoxin aflatoxins $B_{1}$ in 1960 s. The aim of mycotoxins regulations, and establishing acceptable limits of mycotoxins in grains, foods, and animal feeds is to protect human and animals from the harmful effects of mycotoxins. Accepted limits of mycotoxins that was established by each country showed variabilities, these variabilities in mycotoxins acceptable limits demanded international harmonization of mycotoxins regulations and acceptable limits for international trades.

World Health Organization (WHO) in collaboration with Food and Agriculture Organization (FAO) have responsibilities in assessing the health risk of contaminated grains, foods and animal feeds with mycotoxins on human and animals. The outcome from their risk assessments resulted in developing mycotoxins regulations for each mycotoxin in grains, foods and animal feeds. Harmonization of mycotoxins acceptable limits is the responsibility of Codex Alimentarius Commissions (CAC). The aim of Codex Alimentarius Commissions in harmonization of mycotoxins acceptable limits with the support of both $\mathrm{WHO}$, and FAO is to facilitate world trades of agriculture commodities and to protect human and animals' health risk from foods or feeds contaminated with non-acceptable limits of mycotoxins.

Currently there are over 168 countries that are members of Codex Alimentarius, following developed rules and methods published in the Codex procedural Manual for mycotoxins regulations and acceptable limits in grains, foods, and animal feeds.

\section{Conclusions}

Mycotoxins do not only pose health risk to human and animals, but also impact worldwide economy, and food safety. WHO/FAO are responsible to encourage all countries worldwide to monitor mycotoxins levels in their marketed grains, foods and animals' feeds.

Codex Alimentarius, the intergovernmental standard-setting body is responsible for worldwide harmonization of regulations and the accepted limits of mycotoxins in national grains, foods and animal feeds for domestic use and international trades. These worldwide harmonization regulations and standard ac- 
ceptable limits of mycotoxins will improve international trade and give consumers the confidence that marketed grains, foods, and animal feeds have the same safety standards, no matter where it is produced.

\section{Conflicts of Interest}

The authors declare no conflicts of interest regarding the publication of this paper.

\section{References}

[1] Richard, J.L. (2007) Some Major Mycotoxins and Their Mycotoxicosis, an Overview. International Journal of Food Microbiology, 119, 3-10. https://doi.org/10.1016/j.ijfoodmicro.2007.07.019

[2] Milani, J.M. (2013) Ecological Conditions Affecting Mycotoxin Production in Cereals: A Review Veterinarni. Medicina, 58, 405-411. https://doi.org/10.17221/6979-VETMED

[3] Juan-García, A., Manyes, L., Ruiz, M.J. and Font, G. (2013) Applications of Flow Cytometry to Toxicological Mycotoxin Effects in Cultured Mammalian Cells: A Review. Food and Chemical Toxicology, 56, 40-59. https://doi.org/10.1016/j.fct.2013.02.005

[4] Smith, J.E., Solomons, G., Lewis, C. and Anderson, J.G. (1995) Role of Mycotoxins in Human and Animal Nutrition and Health. Natural Toxins, 3, 187-192. https://doi.org/10.1002/nt.2620030404

[5] Mills, J.T. (1990) Mycotoxins and Toxigenic Fungi on Cereal Grains in Western Canada. Canadian Journal of Physiology and Pharmacology, 68, 982-986. https://doi.org/10.1139/y90-149

[6] Bryden, W.L. (2012) Mycotoxin Contamination of the Feed Supply Chain: Implications for Animal Productivity and Feed Security. Animal Feed Science and Technology, 173, 134-158. https://doi.org/10.1016/j.anifeedsci.2011.12.014

[7] Van Egmond, H.P. (1995) Mycotoxins: Regulations, Quality Assurance and Reference Materials. Journal Food Additives and Contaminants, 12, 321-330. https://doi.org/10.1080/02652039509374309

[8] Cotty, P.J. and Jaime-Garcia, R. (2007) Influences of Climate on Aflatoxin Producing Fungi and Aflatoxin Contamination. International Journal of Food Microbiolo$g y, 119,109-115$. https://doi.org/10.1016/j.ijfoodmicro.2007.07.060

[9] Gong, Y., Hounsa, A., Egal, S., Turner, P.C., Sutcliffe, A.E., Hall, A.G., Cardwell, K. and Wild, C.P. (2004) Postweaning Exposure to Aflatoxin Result in Impaired Child Growth: A Longitudinal Study in Benin West Africa. Environmental Health Perspectives, 112, 1334-1338. https://doi.org/10.1289/ehp.6954

[10] Boonen, J., Malysheva, S.V., Taervernier, L., Di Mavungu, J.D., De Saeger, S. and De Spiegelee, P. (2012) Human Skin Penetration of selected Model Mycotoxins. Toxicology, 301, 21-32. https://doi.org/10.1016/j.tox.2012.06.012

[11] Stoloff, L., van Egmond, H.P. and Park, D.L. (1991) Rational for the Establishment of Limits and Regulations for Mycotoxins. Journal Food Additives \& Contaminations, 8, 213-221. https://doi.org/10.1080/02652039109373971

[12] Widestrand, J. and Pettersson, H. (2011) Effect of Time, Temperature, and Solvents on the Stability of T-2 Toxin, HT-2 Toxin, Deoxynivalenol, and Nivalenol Calibrants. Journal of Food Additives \& Contaminants, 18, 987-992. 
https://doi.org/10.1080/02652030110050168

[13] Hardin, B.D., Kelman, B.J. and Saxon, A. (2003) Adverse Human Health Effects Associated with Molds in the Indoor Environment. Journal of Occupational and Environmental Medicine, 45, 470-478. https://doi.org/10.1097/00043764-200305000-00006

[14] Krska, R., Baumgatner, S. and Josephs, R. (2001) The State-of-the-Art in the Analysis of Type-A, and Type-B Trichothecene Mycotoxins in Cereals. Journal of Analytical Chemistry, 371, 285-299.

[15] Ueno, Y. (1984) Toxicological Features of T-2 Toxin and Related Trichothecenes. Fundamental and Applied Toxicology, 4, 124-132. https://doi.org/10.1016/0272-0590(84)90144-1

[16] Adhikari, M., Negi, B., Kaushik, N., Adhikari, A., Al-Khedhairy, A.A., Kaushik, N.K. and Choi, E.H. (2017) T-2 Mycotoxin: Toxicological Effects and Decontamination Strategies. Oncotarget, 8, 33933-33952. https://doi.org/10.18632/oncotarget.15422

[17] Venkataramana, M., Chandranayaka, S., Prakash, H.S. and Niranjana, S.R. (2014) Mycotoxins Relevant to Biowarfare and Their Detection. In: Gopalakrishnakone, P., Ed., Toxicology, Springer, Dordrecht, 1-22. https://doi.org/10.1007/978-94-007-6645-7_32-1

[18] Yang, L.C., Yu, Z.Z., Hou, J.F., Deng, Y.F., Zhou, Z.L., Zhao, Z.Y. and Cui, J. (2016) Toxicity and Oxidative Stress Induced by T-2 Toxin and HT-2 Toxin in Broiler and Broiler Hepatocytes. Food and Chemical Toxicology, 87, 128-137. https://doi.org/10.1016/j.fct.2015.12.003

[19] Kim, D.-W., Kim, G.-Y., Kim, H.-K., Kim, J., Jeon, S.J., Lee, C.W., Lee, H.B. and Yun, S.-H. (2016) Characterization Nivalenol-Producing Fusarium culmorum Isolates Obtained from the Air of Rice Paddy Field in Korea. Plant Pathology Journal, 32, 182-189. https://doi.org/10.5423/PPJ.OA.12.2015.0268

[20] Fink-Gremmels, J., Jahn, A. and Blom, M.J. (1995) Toxicity and Metabolism of Ochratoxin A. Natural Toxins, 3, 214-220. https://doi.org/10.1002/nt.2620030408

[21] Soto, J.B., Fernández-Franzón, M., Ruiz, M.-J. and Juan-García, A. (2014) Presence of Ochratoxin A (OTA) Mycotoxin in Alcoholic Drinks from Southern European Countries: Wine and Beers. Journal of Agricultural and Food Chemistry, 62, 7643-7651. https://doi.org/10.1021/jf501737h

[22] Kolakowski, B., O’Rourke, S.M., Bietlot, H.P., Kurz, K. and Aweryn, B. (2016) Ochratoxin A concentrations in a Variety of Grain-Based and Non-Grain-Based Foods on the Canadian Retail Market from 2009 to 2014. Journal Food Protection, 79, 2143-2159. https://doi.org/10.4315/0362-028X.JFP-16-051

[23] Hope, J.H. and Hope, B.H. (2012) A Review of the Diagnosis and Treatment of Ochratoxin A Inhalational Exposure Associated with Human Illness and Kidney Disease Including Focal Segmental Glomerulosclerosis. Journal of Environmental and Public Health, 2012, Article ID: 835059. https://doi.org/10.1155/2012/835059

[24] Bui-Klimke, T.R. and Wu, F. (2015) Ochratoxin A and Human Health Risk: A Review of the Evidence. Critical Reviews in Food Science and Nutrition, 55, 1860-1869. https://doi.org/10.1080/10408398.2012.724480

[25] Duarte, C., Lino, C.M. and Pena, A. (2010) Mycotoxin Food and Feed Regulation and the Specific Case of Ochratoxin A: A Review of the Worldwide Status. Journal Foods Additives and Contaminants, 27, 1440-1450. https://doi.org/10.1080/19440049.2010.497166

[26] Calvo, A.M. and Cary, J.W. (2015) Association of Fungal Secondary Metabolism 
and Sclerotial Biology. Frontiers in Microbiology, 6, 62. https://doi.org/10.3389/fmicb.2015.00062

[27] Eadie, M.J. (2003) Convulsive Ergotism: Epidemics of Serotonin Syndrome. The Lancet Neurology, 2, 429-434. https://doi.org/10.1016/S1474-4422(03)00439-3

[28] Fajardo J.E., Dexter, J.E., Roscoe, M.M. and Nowicki, T.W. (1995) Retention of Ergot Alkaloids in Wheat during Processing. Cereal Chemistry, 72, 291-298.

[29] Craig, A.M., Klotz, J.L. and Duringer, J.M. (2015) Cases of Ergotism in Livestock and Associated Ergot Alkaloid Concentrations in Feed. Frontiers in Chemistry, 3, 8. https://doi.org/10.3389/fchem.2015.00008

[30] Coufal-Majewski, S., Stanford, K., McAllister, T., Blakley, B., McKinnon, J., Chaves, A.V. and Wang, Y. (2016) Impact of Cereal Ergot in Food Animal Production. Frontiers in Veterinary Science, 3, 15.

[31] Sharma, N., Sharma, V.K., Manikyam, H.K. and Krishna, A. (2016) Ergot Alkaloids: A Review of Therapeutic Applications. European Journal of Medicinal Plants, 14, 1-17. https://doi.org/10.9734/EJMP/2016/25975

[32] Tudzynski, P., Correia, T. and Keller, U. (2001) Biotechnology and Genetics of Ergot Alkaloids. Applied Microbiology and Biotechnology, 57, 593-605. https://doi.org/10.1007/s002530100801

[33] Parsons, M.W. and Munkvold, G.P. (2012) Effects of Planting Date and Environmental Factors on Fusarium Ear Rot Symptoms and Fumonisin $B_{1}$ Accumulation in Maize Grown in Six North American Locations. Plant Pathology, 61, 1130-1142. https://doi.org/10.1111/j.1365-3059.2011.02590.x

[34] Wu, F. (2007) Measuring the Economic Impacts of Fusarium Toxins in Animal Feeds. Animal feed Science and Technology, 137, 363-374. https://doi.org/10.1016/j.anifeedsci.2007.06.010

[35] Rheeder, J.P., Marasas, W.F.O., Thiel, P.G. and Sydenham, E.W. (1992) Fusarium moniliform and Fumonisin in Corn in Relation to Human Esophageal Cancer in Transkei. Phytopathology, 82, 353-357. https://doi.org/10.1094/Phyto-82-353

[36] Wilson, T.M., Ross, P.F., Rice, L.G., Osweiler, G.D., Nelson, H.A., Owens, D.L., Plattner, R.D., Reggiadro, C., Noon, T.H. and Pickrell, J.W. (1990) Fumonisin B Levels Associated with an Epizootic of Equine Leukoencephalomalacia. Journal of Veterinary Diagnostic and Investigation, 2, 213-216. https://doi.org/10.1177/104063879000200311

[37] Rotter, B.A., Thompson, B.K., Prelusky, D.B., Trenholm, H.L., Stewart, B., Miller, J.D. and Savard, M.E. (1996) Response of Growing Swine to Dietary Exposure to Pure Fumonisin $B_{1}$ during an Eight-Week Period: Growth and Clinical Parameters. Natural Toxins, 4, 42-50. https://doi.org/10.1002/19960401NT6

[38] Food and Drugs Administration (FDA) (2001) Guidance for Industry: Fumonisin Levels in Human Foods and Animal Feeds. 9 November 2001.

[39] Abadi, N., Keshavarzi, M., Alaee, H., Hajnajari, H. and Hoseinava, S. (2014) Blue Mold (Penicillium expansum) Decay Resistance in Apple Cultivars, and Its Association with Fruit Physicochemical Traits. Journal of Agricultural Science and Technology, 16, 635-644.

[40] Stinson, E.E., Osman, S.F., Huntanen, C.N. and Bills, D.D. (1978) Disappearance of Patulin during Alcoholic Fermentation of Apple Juice. Environmental Microbiolo$g y, 36,620-622$.

[41] Puel, O., Galtier, P. and Oswald, I.P. (2010) Biosynthesis and Toxicological Effects of Patulin. Toxins (Basel), 2, 613-631. https://doi.org/10.3390/toxins2040613 
[42] Glaser, N. and Stopper, H. (2012) Patulin: Mechanism of Genotoxicity. Food and Chemical Toxicology, 50, 1796-1801. https://doi.org/10.1016/j.fct.2012.02.096

[43] Ioi, J.D., Zhou, T., Tsao, R. and Marcone, M.F. (2017) Mitigation of Patulin in Fresh and Processed Foods and Beverages. Toxins (Basel), 9, 157.

https://doi.org/10.3390/toxins9050157

[44] Shier, W.T., Shier, A.C., Xie, W. and Mirocha, C.J. (2001) Structure-Activity Relationships for Human Estrogenic Activity for Human Estrogenic Activity in Zearalenone Mycotoxins. Toxicon, 39, 1435-1438. https://doi.org/10.1016/S0041-0101(00)00259-2

[45] Collins, T.F.X., Sprando, R.L., Black, T.N., Olejnik, N., Eppley, R.M., Alam, H.Z., Rorie, J. and Ruggles, D.I. (2006) Effects of Zearalenone on in Utero Development in Rats. Food and Chemical Toxicology, 44, 1455-1465. https://doi.org/10.1016/j.fct.2006.04.015

[46] Berek, L., Petri, I.B., Petri, I.B., Mesterházy, Á., Téren, J. and Molná, J. (2001) Effects of Mycotoxins on Human Immune Functions in Vitro. Toxicology in Vitro, 15, 25-30. https://doi.org/10.1016/S0887-2333(00)00055-2

[47] Farnworthand, E.R. and Trenholm, H.L. (1983) The Metabolism of the Mycotoxin Zearalenone and Its Effects on the Reproductive Tracts of Young Male and Female Pigs. Canadian Journal of Animal Science, 63, 967-975. https://doi.org/10.4141/cjas83-111

[48] Mirocha, C.J., Pathre, S.V. and Robison, T.S. (1981) Comparative Metabolism of Zearalenone and Transmission into Bovine Milk. Food and Cosmetics Toxicology, 19, 25-30. https://doi.org/10.1016/0015-6264(81)90299-6

[49] Zinedine, A., Soriano, J.M., Moltó, J.C. and Mañes, J. (2007) Review on the Toxicity, Occurrence, Metabolism, Detoxification, Regulations Regulations and Intake of Zearalenone: An Oestrogenic Mycotoxin. Food and Chemical Toxicology, 45, 1-18. https://doi.org/10.1016/j.fct.2006.07.030

[50] Edwards, S.G. (2004) Influence of Agricultural Practices on Fusarium Infection of Cereals and Subsequent Contamination of Grain by Trichothecene Mycotoxins. Toxicology Letters, 153, 29-35. https://doi.org/10.1016/j.toxlet.2004.04.022

[51] Piecková, E. and Jesenská, Z. (1999) Microscopic Fungi in Dwellings and Their Health Implications in Humans. Annals of Agricultural and Environmental Medicine, 6, 1-11.

[52] Zheng, M.Z., Richard, J.L. and Binder, J. (2006) A Review of Rapid Methods for the Analysis of Mycotoxins. Mycopathologia, 161, 261-273.

https://doi.org/10.1007/s11046-006-0215-6

[53] Turner, N.W., Subrahmanyam, S. and Piletsky, S.A. (2009) Analytical Methods for Determination of Mycotoxins: A Review. Analytica Chimica Acta, 632, 168-180. https://doi.org/10.1016/j.aca.2008.11.010

[54] Kolosova, A.Y., Shim, W.-B., Yang, Z.-Y., Eremin, S.A. and Chung, D.-H. (2006) Direct Competitive ELISA Based on a Monoclonal Antibody for Detection of Aflatoxin $\mathrm{B}_{1}$ Stabilization of ELISA Kit Components and Application to Grain Samples. Analytical and Bioanalytical Chemistry, 384, 286-294.

[55] Oerke, E.-C. and Dehne, H.-W. (2004) Safeguarding Production-Losses in Major Crops and the Role of Crop Protection. Crop Protection, 23, 275-285. https://doi.org/10.1016/j.cropro.2003.10.001

[56] Pirgozliev, S.R., Edwards, S.G., Hare, M.C. and Jenkinson, P. (2003) Strategies for the Control of Fusarium Head Blight in Cereals. European Journal of Plant Pathology, 109, 731-742. https://doi.org/10.1023/A:1026034509247 
[57] Banks, H.J. and Annis, P.C. (1980) Conversion of Existing Grain Storage Structures for Modified Atmosphere Use. Developments in Agricultural Engineering, 1, 461-473. https://doi.org/10.1016/B978-0-444-41939-2.50046-2

[58] Trenholm, H.L., Charmley, L.L., Prelusky, D.B. and Warner, R.M. (1992) Washing Procedures Using Water or Sodium Carbonate for the Decontamination of Three Cereals Contaminated with Deoxynivalenol and Zearalenone. Journal of Agricultural and Food Chemistry, 40, 2147-2151. https://doi.org/10.1021/jf00023a021

[59] Samarajeewa, U., Sen, A.C., Cohen, M.D. and We, C.I. (1990) Detoxification of Aflatoxins in Foods and Feeds by Physical and Chemical Methods. Journal of Food Protection, 53, 489-501. https://doi.org/10.4315/0362-028X-53.6.489

[60] McCormick, S.P. (2013) Microbial Detoxification of Mycotoxins. Journal of Chemical Ecology, 39, 907-918. https://doi.org/10.1007/s10886-013-0321-0

[61] Mazumder, P.M. and Sasmal, D. (2001) Mycotoxins-Limits and Regulation. Ancient Science of Life, 20, 1-19.

[62] Bennett, J.W. and Klich, M. (2003) Mycotoxins. Clinical Microbiology Reviews, 16, 497-516. https://doi.org/10.1128/CMR.16.3.497-516.2003

[63] Smith, M.-C., Madec, S., Coton, E. and Hymery, N. (2016) Natural Co-Occurrence of Mycotoxins in Foods and Feeds and Their in Vitro Combined Toxicological Effects. Toxins (Basel), 8, 94. https://doi.org/10.3390/toxins8040094 